\title{
Coordinating a Service Supply Chain under Arms Offset Program's Intervention by Performance-Based Contracting
}

\author{
Yi-Kuei Lin, Jong-Jang Lin, and Ruey-Huei Yeh \\ Department of Industrial Management, National Taiwan University of Science and Technology, Taipei 10607, Taiwan \\ Correspondence should be addressed to Yi-Kuei Lin; yklin@mail.ntust.edu.tw
}

Received 23 October 2015; Revised 15 January 2016; Accepted 17 January 2016

Academic Editor: Young Hae Lee

Copyright ( 2016 Yi-Kuei Lin et al. This is an open access article distributed under the Creative Commons Attribution License, which permits unrestricted use, distribution, and reproduction in any medium, provided the original work is properly cited.

\begin{abstract}
This paper investigates a support service supply chain for coordinating with a local third-party logistics provider by arms offset program's intervention and develops a performance-based contracting framework for the coordinating problem, which remains scarce in the literatures. The performance-based contracting framework evaluates payments and profits for the support service by a game-theoretical approach with principal-agent model. We prove that the proposed framework is an effective tool in acquiring the balance between maximum profit and minimum payment for both parties in the coordinating problem without moral hazard issue. A numerical study consolidates the formulated schemes as contracting preference for both parties' decision with a higher profit margin at a lower customer's payment.
\end{abstract}

\section{Introduction}

For a complex system (e.g., defense systems, transport vehicles, or oil-platforms), the system support service supply chain is a common and challenging business in global industries today. One of the main drivers in this support service is systems reliability, since the support service revolves around preventing and responding to unanticipated product malfunctions by the service supply chain. Thus the customers (i.e., the systems' owner such as governments or enterprises) have developed an interest in coordinating an after-sales supply chain in order to sustain systems availability to optimize the support service cost and to enhance competitive capabilities or synergies in economical/social field. Generally, fulfilling the increasing support service demands enables the service supply chains to generate higher profit margins than systems' sales and to constitute a significant part of the industrial economy [1].

Since the system support services are often provided and consumed by two different organizations (i.e., the customer and the service provider), the issue of contracting between them becomes important. In practice, the service supply chain for system support service is categorized into a resource-based contract (RBC) and a performance-based contract (PBC). The RBC is a traditional systems' support strategy by amounting resources such as spare parts, labors, and consumable resources in contract duration. By contrast, the PBC contains a service level agreement with respect to a system performance output (e.g., the system availability) at the consumer site and concentrates on performance results rather than on material results as huge-crowd strategy traditionally done. The strategy is often referred to as "performance-based logistics" (PBL) in defense industry or "power by hour" logistics (PBH) in commercial airlines [2].

However, for military system support service, most studies referred more generally to the customer (i.e., purchasing country, $G_{P}$ ) along with the service supply chain by system's original equipment manufacturers (OEM) relation $\left(G_{P}-\right.$ OEM) and, namely, lacked attentions on the customer along with a domestic third-party logistics providers (3PL) relation $\left(G_{P}-3 \mathrm{PL}\right)$. The $G_{P}-3 \mathrm{PL}$ support service is usually induced by arms offset program, which is widely implemented in the newly industrial countries such as Taiwan [3]. In national arms sales, the arms offset program becomes an essential condition by offering from the OEM. It is a global interactive business driven through the defense OEM (e.g., Boeing or Lockheed Martin) that transfers extra technical or economic benefits to the customer as an incentive mechanism for selling 


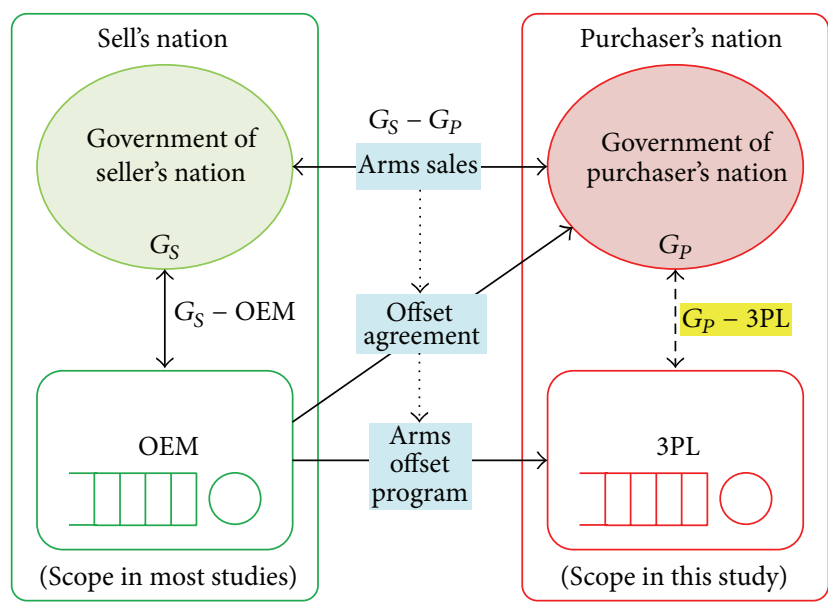

Figure 1: The correlations among $G_{S}, G_{P}$, OEM, and 3PL.

defense systems or services in governmental procurement [4]. Based on the practices in Taiwan [3], a typical arms offset program starts with the arms sale between the customer and the OEM's nation (e.g., US, $G_{S}$ ). Follow the arms sales deal $\left(G_{S}-G_{P}\right)$; the OEM has to fulfill the offset obligations by rewarding the customer's requirements for enriching the customer's economy synergy [5]. Figure 1 presents the close loop correlations and compares different types of the service supply chain form by the OEM and 3PL.

Additionally, most literatures are generally limited into the advantages of support service relations between $G_{S}-$ OEM and $G_{P}-$ OEM service supply chain [1, 6-9], which seldom address themselves to $G_{P}-3 P L$ service supply chain relation under arms offset program's intervention. Hence, the shortcomings for $G_{P}-3 \mathrm{PL}$ coordinating problem provide a research opportunity. In this paper, we develop an enhanced PBC model, which was proposed by Kim et al. [1], for $G_{P}-3 \mathrm{PL}$ coordinating problem. Specifically, we address the following research questions:

(1) How do they interact in $G_{P}-3 P L$ service supply chain relation by intervention from arms offset program?

(2) How to make a quantifiable assessment to approach the customer's minimum payment for budget planning and 3PL's maximum profit before start bargaining for $G_{P}-3$ PL coordinating problem? Additionally, how does the quantifiable assessment influence decisions for $G_{P}-3 P L$ service supply chain relation?

For the coordinating problem for $G_{P}-3 P L$ service supply chain, this paper develops a coordinating framework by using the principle-agent model and game-theoretic analysis to assess a rational decision preference for the coordinating problem of $G_{P}-3 \mathrm{PL}$ service supply chain with multiple $\mathrm{PBC}$ schemes in a self-interested manner. The remainder of this paper is organized as follows. Section 2 summarizes the literatures related to the PBC. Section 3 defines the proposed coordinating framework. Section 4 implements a practical coordinating problem for $G_{P}-3 \mathrm{PL}$ service supply chain in
Taiwan to demonstrate how the framework presents qualitative and quantitative analyses into the problem. Section 5 draws conclusions and gives directions for future research.

\section{Literature Overview}

Since large numbers of literatures referred to service supply chain optimization, which has been widely measured by performance outcome characteristic such as system availability, thus this section concentrates on the research tendency in the PBC territories in principal-agent based approach and operational availability based approach. Furthermore, considering literatures on the redundancy allocation and conceptual principle-agent framework allows us to discover a new research tendency and develop a quantitative decision framework for assessing $G_{P}-3 \mathrm{PL}$ coordinating problem.

Our study is closely related to the design and deployment of profitable close-loop service supply chain by using principal-agent based approach, which has examined the principal-agent model for PBC. Scherer [10] introduced the theory of contract incentives for optimal cost premium under risk aversion conditions in defense procurement. McAfee and McMillan [11] introduced an analysis of bidding for government procurement under significant cost-related risks. As the complexity of the products and production processes increased, the contracting strategy of managing production processes from basic raw material resources to sophisticated products became a less viable option [12]. Additionally, Ashgarizadeh and Murthy [13] indicated that maintenance outsourcing by an external agent may be specified for maintenance and cost issues and develop a stochastic model to study the impacts on the agents' expected profits and the optimal strategies by using a game theoretic formulation.

Several models were developed to encompass numerous conflicting objectives from both principal and agents because maintenance contracts were growing more complex. Bowman and Schmee [14] performed a simulation to explore the operational issues and sensitivities associated with these contracts and examined a case of aircraft engine maintenance service in a large corporation to help mitigate and manage uncertainty risks. Kim et al. [1] focused on outcomebased reimbursement policies for risk aversion by using the principal-agent model and studied cost-plus and fixed-price contracts in the context of logistics support to measure the after-sales supply chain. Additionally, Kim et al. [6] also compared efficiencies of two widely used contracts, based on sample-average downtime and cumulative downtime, and identified the supplier's ability to influence the frequency of disruptions as an important factor in determining which contract performs better. Öner et al. [15] introduced a quantitative model to support the decision on the reliability level of a critical component during the design phase to formulate the costs, which were affected by the reliability level of the component and its spare parts inventory throughout a service contract. Finally, Fang and Wong [16] applied a hybrid casebased reasoning approach in the pre- and postnegotiation phases to support adaptive negotiation strategy for buyerseller negotiations in SCM applications; Yu and Wong [17] presented an agent based negotiation model to automate 
the supplier selection process involving a bundle of products with synergy effect; Jin et al. [18] proposed a principalagent model by attaining multiple objectives such as maximizing the service profitability, lowering the support cost, and ensuring the system availability; and Liu et al. [19] focus on the revenue-sharing contract mechanism design of two stages of service supply chain with consideration of customer customization demand on the background of mass customization service.

In operational availability based approach, it has become a greater concern in recent years because of a large number of literatures on availability optimization for high-tech industrial processes. Kuo and Wan [20] indicated that all these models dealt with either one or both problems for optimizing a system's availability.

(I) Availability Allocation. Components or subsystems are appropriately chosen such that the overall system availability is either maximized or meets the design requirement by deciding which option to choose among alternatives (with the same functionality) or to what level to improve the availability of the component.

(II) Redundancy Allocation. It is a technique to put extra parts into the system as failure backups. The actual implementation of this approach is often subject to design or resource constraint by deciding how many identical components to use in parallel.

For both allocations, Öner et al. [15] indicated that the system's availability might be increased by providing a higher investment in system's design to conclude an optimization against certain constraints such as budgetbalance, performance, acquisition, production, or operation. Additionally, researches for both availability and redundancy allocations usually concentrated on cost issues before system's acquisition phase (e.g., material acquisition, design, and manufacturing); thus they often result in suboptimal solution by ignoring the after-sales services (e.g., logistics and maintenance) costs [2]. Hence, the PBC was widely applied into industrial practices such as modeling supply chain performance and stability $[1,6]$, green supply chain management [21], making decisions on integrating production and maintenance [22], and coordination for fixed lifetime products with permissible delay in payments [23].

By reviewing the aforementioned literatures, most of them concentrated on an OEM response to its own system's performance output (e.g., availability) through various contracting schemes. As a result, the coordinating problem for $G_{P}-3$ PL service supply chain remains scarce in the literatures. Hence this paper aims at $G_{P}-3 \mathrm{PL}$ coordinating problem as in the field through support service contract under a service supply chain with given reliability level, which is a necessary complement on principle-agent approach in the PBC.

\section{Model Formulation}

In this section, we formulate a coordinating framework by using the principle-agent model and game-theoretic approach to assess a rational decision preference for a $G_{P}-$ $3 \mathrm{PL}_{i}$ coordinating problem. In the absence of coordination, both of the parties make decisions to minimize their own costs and maximize their expected utilities such as performance outcome or service profit. Notations used in this paper are listed as follows:

$a_{i}: 3 \mathrm{PL}_{i}$ 's cost reduction effort.

$B_{i}: 3 \mathrm{PL}_{i}$ 's backorder.

$c_{i}: 3 \mathrm{PL}_{i}$ 's fixed cost.

$C_{i}: 3 \mathrm{PL}_{i}$ 's total cost.

$f_{i}(x)$ : ith system's probability density function (PDF).

$F_{i}(x)$ : ith system's cumulative distribution function (CDF).

$G_{P}$ : the country that purchases $i$ th system.

$G_{S}$ : the OEM's country who sells $i$ th system.

$|\bar{H}|:$ Bordered Hessian determinant.

$k_{i}$ : a parameter for $3 \mathrm{PL}_{i}$ 's incurring disutility $\psi\left(a_{i}\right)$.

$L_{i}: 3 \mathrm{PL}_{i}$ 's repair lead time distribution for the system.

$n$ : distinct systems in a vehicle.

$M$ : numbers of vehicle in a fleet.

$O_{i}: 3 \mathrm{PL}_{i}$ 's repair pipeline (on-order).

$q_{i}$ : frequency summation of $G_{P}$ 's $E\left[U_{p}\left(T_{i}\left(C_{i}, B_{i}\right)\right)\right]$ and $3 \mathrm{PL}_{i}$ 's $E\left[U_{i}\left(T_{i}\left(C_{i}, B_{i}\right)\right)\right]$.

$r_{i}: 3 \mathrm{PL}_{i}$ 's risk aversion ratio.

$S_{i}$ : ith system's inventory level, which is set by $G_{P}$.

$T_{C}\left(C_{i}, B_{i}\right)$ : cost-plus outsourcing scheme.

$T_{F}\left(C_{i}, B_{i}\right)$ : fixed price outsourcing scheme.

$T_{P}\left(C_{i}, B_{i}\right)$ : fixed price combined with penalty item outsourcing scheme.

$T_{B}\left(C_{i}, B_{i}\right)$ : performance-based outsourcing scheme.

$\alpha_{i}$ : cost premium weighting factor in contract.

$\varepsilon_{i}: 3 \mathrm{PL}_{i}$ 's uncertainty in total cost.

$\delta_{i}$ : Lagrange multiplier.

$\eta_{h i}: 3 \mathrm{PL}_{i}$ 's hardware cost.

$\eta_{a i}: 3 \mathrm{PL}_{i}$ 's software cost.

$\eta_{m i}: 3 \mathrm{PL}_{i}$ 's unit cost for maintenance actions.

$\lambda_{i}$ : Poisson rate.

$\mu_{i}$ : number of failed system.

$v_{i}$ : penalty weighting factor in contract.

$\psi_{i}\left(a_{i}\right): 3 \mathrm{PL}_{i}$ 's incurring disutility.

$\omega_{i}: G_{P}$ 's budget constrain. 


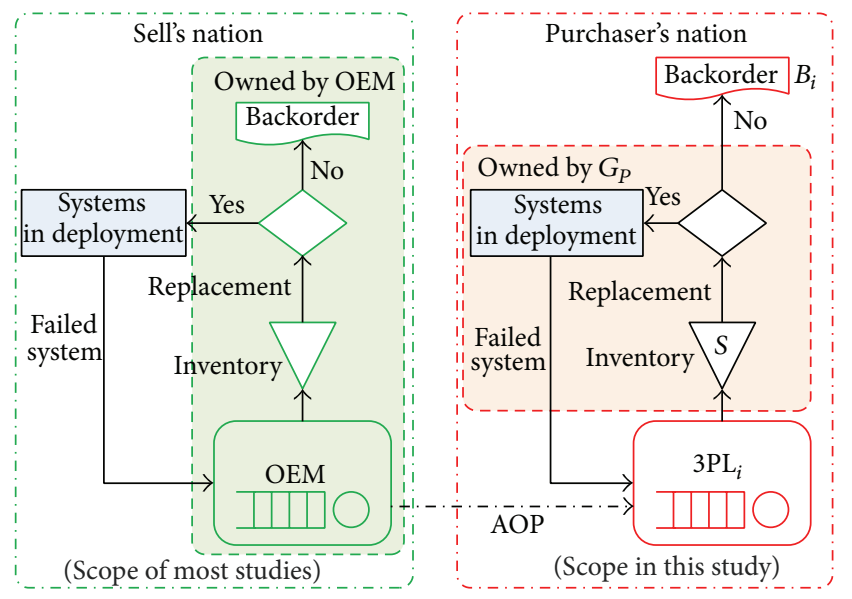

FIGURE 2: The varied coordinating problems between the OEM and $3 \mathrm{PL}_{i}$ supply chain.

3.1. Problem Statements. Consider the coordinating problem under $G_{P}-3 \mathrm{PL}$ supply chain for a system support service. The principal is $G_{P}$ that acquires $N$ identical assembled vehicles (e.g., helicopter or jet fighter). Each vehicle is composed of $n$ distinct major systems (e.g., jet engine or avionics) and each of them can be maintained by a chosen $3 \mathrm{PL}_{i}$ through the arms offset program to fulfill the $G_{P}$ 's strategies for cultivating $G_{P}$ 's local industries. Assume no system is discarded during the vehicle's entire lifecycle because the system is typically expensive and has a long-turn operational lifecycle. Failures occur with a Poisson rate $\lambda_{i}$ and independently from failures of other systems; thus $\operatorname{Cov}\left[\lambda_{i}, \lambda_{j}\right]=0, \forall i \neq j$.

Notably, $G_{P}$ maintains an inventory of spared system and employs one-for-one base stock policy. The inventory is very unique but reasonable for the following considerations. First, in most arms sales cases, the $G_{P}$ usually purchases extra systems in advance to prevent uncertainties, such that $G_{P}$ fails bargain with the chosen $3 \mathrm{PL}_{i}$ or the OEM does not release maintenance technologies to $3 \mathrm{PL}_{i}$ through an arms offset program [24]. Second, such inventory policy allows for an immediate replacement while a failed system enters $3 \mathrm{PL}_{i}$ 's repair facility or occurs as a backorder $B_{i}$ to affect system's availability. Figure 2 illustrates the maintenance sequence comparisons between the current $G_{P}-$ OEM and proposed $G_{P}-3 \mathrm{PL}_{i}$.

The backorder $B_{i}$ in the service supply chain is related with a given inventory level $S_{i}$ and a stationary random pipeline (on-order) $O_{i}$ at a random point in time through $E\left[B_{i} \mid S_{i}\right]=\left(O_{i}-S_{i}\right) \geq 0$. Furthermore, Palm's theorem states that $O_{i}$ is Poisson distributed for any repair lead time distribution, with the mean $\mu_{i} \equiv \lambda_{i} L_{i}$. The failure rate's approximation is close to be fixed because $\lambda_{i}$ is the amount of failure units in the maintenance sequence. In practice, consider $E\left[B_{i} \mid S_{i}\right] \leq \lambda_{i} L_{i} \ll n_{i} N+S_{i}$ is satisfied for most repairable systems. This assumption ensures the amount of system maintenance at any given time is relatively small and ignores the correction caused by state dependency.

Proposition 1. The expected backorder $E\left[B_{i} \mid S_{i}\right]$ is decreasing and convex in $S_{i}$.
Proof. Let the repair pipeline $O_{i} \in[0, \infty)$ be distributed continuously by a cumulative distribution function (CDF) $F_{i}\left(O_{i}\right) \in[0,1]$ and a probability density function (PDF) $f_{i}$. Thus the distribution of $B_{i}$ is obtained by determining $\operatorname{Pr}\left(B_{i} \leq\right.$ $\left.x \mid S_{i}\right)=\operatorname{Pr}\left(O_{i} \leq x+S_{i}\right)$.

Furthermore, consider the expected backorder $E\left[B_{i}\right.$ । $\left.S_{i}\right]=\int_{S_{i}}^{\infty}\left(1-F_{i}(x)\right) d x$; therefore the $d E\left[B_{i} \mid S_{i}\right] / d S_{i}=$ $-1+F_{i}\left(S_{i}\right) \leq 0$ and $d E^{2}\left[B_{i} \mid S_{i}\right] / d S_{i}^{2}=f_{i}\left(S_{i}\right) \geq 0$.

Hence we conclude the expected backorder $E\left[B_{i} \mid S_{i}\right]$ is decreasing and convex in $S_{i}$.

3.2. Coordinating Contracting Terms and Utilities. For generating $3 \mathrm{PL}_{i}$ 's total cost $C_{i}$ for the support service, we firstly consider $3 \mathrm{PL}_{i}$ 's fixed cost $c_{i}=\eta_{h i}+\eta_{a i}+\eta_{m i} E\left[u_{i}\right]$, where $\eta_{h i}$ denotes hardware costs to construct facility, $\eta_{a i}$ denotes software costs such as intellectual authorities or technical assistance from the OEM, $\eta_{m i}$ denotes unit cost for maintenance, and $E\left[u_{i}\right]$ represents expected demands in contract duration. In practices, the fixed cost $c_{i}$ may be reduced by $3 \mathrm{PL}_{i}$ 's cost reduction effort $a_{i}$ with an incurring disutility $\psi_{i}\left(a_{i}\right)$, which is increasing convex (i.e., $\psi_{i}^{\prime}\left(a_{i}\right)>0$ and $\psi_{i}^{\prime \prime}\left(a_{i}\right)>0$ ) and which can be assessed by $G_{P}$. In this convention, the cost reduction effort $a_{i}$ is $3 \mathrm{PL}_{i}$ 's own discretionary decision; hence $G_{P}$ does not subsidize $3 \mathrm{PL}_{i}$ 's internal cost but only reimburses the undisputed direct costs of maintenance. Chen [25] presented a quadratic functional form to verify the disutility $\psi_{i}\left(a_{i}\right)$ through $\psi\left(a_{i}\right)=k_{i} a_{i}^{2} / 2, \forall k_{i} \in R^{+}$. This assumption generates compact expressions without fundamentally changing the insights of the framework.

Secondly, Laffont and Tirole [26] introduced a relationship to generate the basis of the $3 \mathrm{PL}_{i}$ 's total reimbursement cost $C_{i}=c_{i}-a_{i}+\varepsilon_{i}$, where $\varepsilon_{i}$ denotes the uncertainty. Let $\varepsilon_{i}$ be uncorrelated with the backorder $B_{i}$ and another different system, which is supported by a $3 \mathrm{PL}_{j}(\forall i \neq j)$; thus $\operatorname{Cov}\left[\varepsilon_{i}, B_{i}\right]=\operatorname{Cov}\left[\varepsilon_{i}, \varepsilon_{j}\right]=\operatorname{Cov}\left[\varepsilon_{i}, B_{j}\right]=0$. Notably, this assumption does not consider $3 \mathrm{PL}_{i}$ 's efforts impact on the availability and repair capabilities of the system, with or without extra technical assistance from the system's OEM.

Thirdly, Kim et al. [1] integrated contract payment terms by comprising a fixed payment $\omega_{i}$, a reimbursement cost $C_{i}$, and a backorder-contingent incentive payment $B_{i}$ to construct the $\mathrm{PBC}$ form through

$$
T_{i}\left(C_{i}, B_{i}\right)=\omega_{i}+\alpha_{i} C_{i}-v_{i} B_{i} \eta_{m}
$$

where $\alpha_{i} \in(0,1)$ denotes the $G_{P}$ 's cost-premium weighting factor for $3 \mathrm{PL}_{i}$ and $v_{i} \in(0,1)$ denotes the penalty weighting rate for unacceptable outcomes such as $E\left[B_{i} \mid S_{i}\right]$.

Additionally, considering that $3 \mathrm{PL}_{i}$ is risk aversion, Chen [25] presented that $3 \mathrm{PL}_{i}$ 's net income is normally distributed and the expected mean-variance utility can be estimated as

$$
E[U(x)]=\vartheta_{x}-\frac{r}{2} \sigma_{x}^{2}
$$

where $x$ denotes the normal distributed net income, $\vartheta_{x}$ represents the mean of $x$, and $\sigma_{x}^{2}$ presents the variance. Furthermore, $r \geq 0$ denotes a constant risk aversion factor, such that the greater the $r$ is, the more the risk aversion 
$3 \mathrm{PL}_{i}$ has. This utility function has been widely used in recent operations-management research because of its tractability and allows us to derive the expected profit function for $3 \mathrm{PL}_{i}$ by various contract scheme $T\left(C_{i}, B_{i}\right)$ through

$$
\begin{aligned}
E\left[U_{i}\left(T\left(C_{i}, B_{i}\right)-C_{i}\right)-\psi_{i}\left(a_{i}\right) \mid a_{i}, S_{i}\right] \\
=\omega_{i}-\left(1-\alpha_{i}\right)\left(C_{i}-a_{i}\right)-v_{i} E\left[B_{i} \mid S_{i}\right]-\frac{k_{i} a_{i}^{2}}{2} \\
\quad-\frac{\left(r_{i}\left(1-\alpha_{i}\right)^{2} \operatorname{Var}\left[\varepsilon_{i}\right]-r_{i} v_{i}^{2} \operatorname{Var}\left[B_{i} \mid S_{i}\right]\right)}{2}
\end{aligned}
$$

where $\omega_{i}-\left(1-\alpha_{i}\right)\left(C_{i}-a_{i}\right)-v_{i} E\left[B_{i} \mid S_{i}\right]$ term represents the expected income, $-k_{i} a_{i}^{2} / 2$ term represents the internal disutility for exerting cost reduction efforts, and $-\left(r_{i}(1-\right.$ $\left.\left.\alpha_{i}\right)^{2} \operatorname{Var}\left[\varepsilon_{i}\right]-r_{i} v_{i}^{2} \operatorname{Var}\left[B_{i} \mid S_{i}\right]\right) / 2$ term represents risk premiums associated with cost and performance uncertainties with $\operatorname{Var}\left[B_{i} \mid S_{i}\right]$.

Similarly, the expected payment (i.e., budget constraint) utility function $E\left[U_{p}\left(T_{i}\left(C_{i}, B_{i}\right)\right) \quad \mid a_{i}, S_{i}\right]$ for the support service can be derived through

$$
\begin{aligned}
E\left[U_{p}\left(T_{i}\left(C_{i}, B_{i}\right)\right) \mid a_{i}, S_{i}\right] & \\
= & \omega_{i}-\alpha_{i}\left(C_{i}-a_{i}\right)-v_{i} E\left[B_{i} \mid S_{i}\right]+\frac{r_{i} \alpha_{i}^{2} \operatorname{Var}\left[\varepsilon_{i}\right]}{2} \\
& +\frac{r_{i} v_{i}^{2} \operatorname{Var}\left[B_{i} \mid S_{i}\right]}{2},
\end{aligned}
$$

where $\omega_{i}-\alpha_{i}\left(C_{i}-a_{i}\right)-v_{i} E\left[B_{i} \mid S_{i}\right]$ represents expected net payment.

\subsection{Game-Theoretic Analysis to Generate Dominate Strategy.} This subsection considers $G_{P}-3 \mathrm{PL}$ coordinating problem is enforced by Nash bargaining in using cooperative game theory because both parties constitute a coalition by selecting contracting schemes and enforcement [27]. Thus the objectives for $G_{P}-3 \mathrm{PL}$ coordinating problem can be summarized as

(I) Determine appropriate incentives through an AOP to a chosen domestic $3 \mathrm{PL}_{i}$ for enriching $G_{P}$ 's economic utilities.

(II) Access $G_{P}$ 's preference decision by determining a minimal payment and $3 \mathrm{PL}_{i}$ 's maximal profit for the support service.

Additionally, the total cost $C_{i}$ and backorder level $B_{i}$ are functions of the cost reduction effort $a_{i}$ and the $i$ th system's inventory $S_{i}$. This allows $3 \mathrm{PL}_{i}$ to partially control the performance by setting $a_{i}$ to maximize $G_{P}$ 's expected profit and risk-averse. Hence, $3 \mathrm{PL}_{i}$ 's actions can be observable by $G_{P}$ to access the effectiveness with widely used contracting schemes by controlling $v_{i}$ and $\alpha_{i}$ through (3) and (4).

Scheme 2. A pure fixed price contract $T_{F}\left(C_{i}, B_{i}\right)$ by $v_{i}=0$ and $\alpha_{i}=0$; thus, the contracting term is $T_{F}\left(C_{i}, B_{i}\right)=\omega_{i}$.
TABLE 1: Normal-form game for various coordinating schemes.

$3 \mathrm{PL}_{i}$

$\alpha_{i}=0 \quad 0<\alpha_{i}<1$

\begin{tabular}{lcc}
\hline$G_{P}$ & & \\
$v_{i}=0$ & $T_{F}\left(C_{i}, B_{i}\right)=\omega_{i}$ & $T_{C}\left(C_{i}, B_{i}\right)=\omega_{i}+\alpha_{i} C_{i}$ \\
$0<v_{i}<1$ & $T_{P}\left(C_{i}, B_{i}\right)=\omega_{i}-v_{i} B_{i}$ & $T_{B}\left(C_{i}, B_{i}\right)=\omega_{i}+\alpha_{i} C_{i}-v_{i} B_{i}$ \\
\hline
\end{tabular}

Scheme 3. A fixed price contract with penalty items $T_{P}\left(C_{i}, B_{i}\right)$ by $0<v_{i}<1$ and $\alpha_{i}=0$ results in $T_{P}\left(C_{i}, B_{i}\right)=\omega_{i}-v_{i} B_{i}$.

Scheme 4. A cost-plus contract $T_{C}\left(C_{i}, B_{i}\right)$ with full reimbursement by $v_{i}=0$ and $0<\alpha_{i}<1$ results in $T_{C}\left(C_{i}, B_{i}\right)=$ $\omega_{i}+\alpha_{i} C_{i}$.

Scheme 5. A performance-based contract $T_{B}\left(C_{i}, B_{i}\right)$ by $0<$ $v_{i}<1$ and $0<\alpha_{i}<1$ results in $T_{B}\left(C_{i}, B_{i}\right)=\omega_{i}+\alpha_{i} C_{i}-v_{i} B_{i}$.

Table 1 shows all four schemes (i.e., feasible strategies) for $G_{P}-3 \mathrm{PL}_{i}$ 's coordinating problem within a two-player normal-form game for theoretic analysis.

In practices, Table 1 is sufficient to represent a portfolio for both parties' perspectives. First, $G_{P}$ desires to access a minimal budget-balancing and risks for system availability by regarding penalties $v_{i}$ to ensure $G_{P}$ 's claim. Second, the $3 \mathrm{PL}_{i}$ desires to access 3PL maximal profits by determining a costsharing effort $\alpha_{i}$. Table 2 represents the expected utility for four contracting schemes by substituting (3) and (4).

In a $G_{S}-G_{P}$ arms sales case, $G_{P}$ sets inventory $S_{i}$, selects contract terms $\left(\omega_{i}, \alpha_{i}, v_{i}\right)$ and proceeds to anticipate $3 \mathrm{PL}_{i}$ 's effort $a_{i}$ to achieve a minimal total disutility, which subjects to the $i$ th system's availability requirement (i.e., the backorder constraint $B_{i}$ ). Therefore $3 \mathrm{PL}_{i}$ chooses $a_{i}$ to maximize $3 \mathrm{PL}$ expected profit utility by giving contracting schemes and parameters $\left(\omega_{i}, \alpha_{i}, v_{i}, S_{i}\right)$. Hence $3 \mathrm{PL}_{i}$ solves $3 \mathrm{PL}$ maximal expected utility problem by evaluating schemes which subject to $\max _{a_{i}} \operatorname{Arg}_{T\left(C_{i}, B_{i}\right)} E\left[U_{i}\left(T\left(C_{i}, B_{i}\right)-C_{i}\right)-\psi_{i}\left(a_{i}\right) \mid a_{i}, S_{i}\right]>0$ within the individual rationality constraint $\left(\mathrm{IR}_{t}\right)$ to ensure the $3 \mathrm{PL}_{i}$ 's participation. This becomes a typical moral hazard problem to allow each $\mathrm{IR}_{t}$ to bind at the optimal solution $[1,24]$. Similarly, $G_{P}$ can exact all surplus from $3 \mathrm{PL}_{i}$ by setting an appropriate fixed payment $\left(\omega_{i}\right)$ to solve $G_{P}$ 's problem as $\min _{\omega_{i}, \alpha_{i}, v_{i}, S_{i}} \operatorname{Arg}_{T\left(C_{i}, B_{i}\right)} E\left[U_{p}\left(T_{i}\left(C_{i}, B_{i}\right)\right) \mid a_{i}, S_{i}\right]$.

Additionally, $3 \mathrm{PL}_{i}$ 's cost reduction effort $a_{i}$ is observable in real arms offset program practices (i.e., the first-best solution in principle-agent model). Let $\delta_{i}$ be the Lagrangemultiplier which associates with the system availability constraint to convert the expected utility with Lagrangian $L_{i}=$ $E\left[U_{i}-\psi_{i}\right]-\delta_{i} E\left[U_{P}\right]$ with (3) and (4) to determine partial derivatives of $\partial L_{i} / \partial a_{i}, \partial L_{i} / \partial r_{i}$, and $\partial L_{i} / \partial \delta_{i}$ as

$$
\begin{aligned}
& a_{i}=\frac{1}{k_{i}}, \\
& r_{i}=\frac{2\left(C_{i}-\omega_{i}+\alpha_{i}\left(C_{i}-1 / k_{i}\right)+v_{i} E\left[B_{i} \mid S_{i}\right]\right)}{\left(\alpha_{i}^{2} \operatorname{Var}\left[\varepsilon_{i}\right]+v_{i}^{2} \operatorname{Var}\left[B_{i} \mid S_{i}\right]\right)},
\end{aligned}
$$


TABLE 2: Expected utility of various outsourcing schemes.

\begin{tabular}{lcc}
\hline Scheme & $G_{P}$ & $3 \mathrm{PL}_{i}$ \\
\hline$T_{F}\left(C_{i}, B_{i}\right)$ & $\omega_{i}$ & $\omega_{i}-\left(C_{i}-a_{i}\right)$ \\
$T_{P}\left(C_{i}, B_{i}\right)$ & $\omega_{i}-v_{i} E\left[B_{i} \mid S_{i}\right]+r_{i} v_{i}^{2} \frac{\operatorname{Var}\left[B_{i} \mid S_{i}\right]}{2}$ & $\omega_{i}-\left(C_{i}-a_{i}\right)-v_{i} E\left[B_{i} \mid S_{i}\right]-\frac{k_{i} a_{i}^{2}}{2}-r_{i} \frac{\operatorname{Var}\left[\varepsilon_{i}\right]}{2}-r_{i} v_{i}^{2} \frac{\operatorname{Var}\left[B_{i} \mid S_{i}\right]}{2}$ \\
$T_{C}\left(C_{i}, B_{i}\right)$ & $\omega_{i}-\alpha_{i}\left(C_{i}-a_{i}\right)+r_{i} \alpha_{i}^{2} \frac{\operatorname{Var}\left[\varepsilon_{i}\right]}{2}$ & $\omega_{i}-\left(1-\alpha_{i}\right)\left(C_{i}-a_{i}\right)-\frac{k_{i} a_{i}^{2}}{2}-r_{i}\left(1-\alpha_{i}\right)^{2} \frac{\operatorname{Var}\left[\varepsilon_{i}\right]}{2}$ \\
$T_{B}\left(C_{i}, B_{i}\right)$ & $\omega_{i}-\alpha_{i}\left(C_{i}-a_{i}\right)-v_{i} E\left[B_{i} \mid S_{i}\right]+r_{i} \alpha_{i}^{2} \frac{\operatorname{Var}\left[\varepsilon_{i}\right]}{2}$ & $\omega_{i}-\left(1-\alpha_{i}\right)\left(C_{i}-a_{i}\right)-v_{i} E\left[B_{i} \mid S_{i}\right]-\frac{k_{i} a_{i}^{2}}{2}$ \\
\hline & $+r_{i} v_{i}^{2} \frac{\operatorname{Var}\left[B_{i} \mid S_{i}\right]}{2}$ & $-r_{i}\left(1-\alpha_{i}\right)^{2} \frac{\operatorname{Var}\left[\varepsilon_{i}\right]}{2}-r_{i} v_{i}^{2} \frac{\operatorname{Var}\left[B_{i} \mid S_{i}\right]}{2}$
\end{tabular}

$$
\delta_{i}=\frac{\left(\left(1-\alpha_{i}\right)^{2} \operatorname{Var}\left[\varepsilon_{i}\right]-v_{i}^{2} \operatorname{Var}\left[B_{i} \mid S_{i}\right]\right)}{\left(\alpha_{i}^{2} \operatorname{Var}\left[\varepsilon_{i}\right]+v_{i}^{2} \operatorname{Var}\left[B_{i} \mid S_{i}\right]\right)}
$$

Proposition 6. In $T_{P}\left(C_{i}, B_{i}\right), T_{C}\left(C_{i}, B_{i}\right)$, and $T_{B}\left(C_{i}, B_{i}\right)$, $\operatorname{Arg}_{T\left(C_{i}, B_{i}\right)} E\left[U_{i}-\psi_{i}\right]$ is decreasing and convex in $\alpha_{i}$ and $v_{i}$.

Proof. For $3 \mathrm{PL}_{i}$ 's expected utilities are subjected to $G_{P}$ 's constrained budget; the second-order necessary-and-sufficient conditions encompass the algebraic sign of the second-order partial differential $\partial^{2} L$ at a stationary point by the Bordered Hessian determinant $\operatorname{Arg}_{T\left(C_{i}, B_{i}\right)}\left|\overline{H_{i}}\right|$ [28] to determine the second-order necessary-and-sufficient condition:

$$
\begin{aligned}
\underset{T\left(C_{i}, B_{i}\right)}{\operatorname{Arg}}\left|\overline{H_{i}}\right| & =\left|\begin{array}{ccc}
0 & \frac{\partial L}{\partial \alpha_{i}} & \frac{\partial L}{\partial r_{i}} \\
\frac{\partial L}{\partial \alpha_{i}} & \frac{\partial^{2} L}{\partial \alpha_{i}^{2}} & \frac{\partial^{2} L}{\partial \alpha_{i} \partial r_{i}} \\
\frac{\partial L}{\partial r_{i}} & \frac{\partial^{2} L}{\partial r_{i} \partial \alpha_{i}} & \frac{\partial^{2} L}{\partial r_{i}^{2}}
\end{array}\right| \\
& =\frac{k_{i}\left(\alpha_{i}^{2} \operatorname{Var}\left[\varepsilon_{i}\right]+v_{i}^{2} \operatorname{Var}\left[B_{i} \mid S_{i}\right]\right)}{4}
\end{aligned}
$$

given $\forall k_{i}>0, \operatorname{Var}\left[\varepsilon_{i}\right]>0$, and $\operatorname{Var}\left[B_{i} \mid S_{i}\right]>0$ to determine various schemes $\left|\overline{H_{i}}\right|$. In Scheme 2 (i.e., $T_{F}\left(C_{i}, B_{i}\right)$ with $\left.v_{i}=\alpha_{i}=0\right), \operatorname{Arg}_{T_{F}}\left|\overline{H_{i}}\right|=0$ concludes that the second-order sufficient condition is not satisfied for maximum $\operatorname{Arg}_{T\left(C_{i}, B_{i}\right)} E\left[U_{i}-\psi_{i}\right]$. In $T_{P}\left(C_{i}, B_{i}\right), T_{C}\left(C_{i}, B_{i}\right)$, and $T_{B}\left(C_{i}, B_{i}\right)$ schemes, $\operatorname{Arg}_{T\left(C_{i}, B_{i}\right)}\left|\overline{H_{i}}\right|>0$ by giving $v_{i}>0$ or $\alpha_{i}>0$.

Hence we conclude in $T_{P}\left(C_{i}, B_{i}\right), T_{C}\left(C_{i}, B_{i}\right)$, and $T_{B}\left(C_{i}, B_{i}\right)$ that $\operatorname{Arg}_{T\left(C_{i}, B_{i}\right)} E\left[U_{i}-\psi_{i}\right]$ is decreasing and convex in $a_{i}$ and $v_{i}$.

Proposition 6 proves $T_{F}\left(C_{i}, B_{i}\right)$ is not a satisfied maximum expected utilities because the $T_{F}\left(C_{i}, B_{i}\right)$ totally ignores $3 \mathrm{PL}_{i}$ 's effort $a_{i}$ and $\operatorname{Var}\left[B_{i} \mid S_{i}\right]$, but this result can be a benchmark against other contracting alternatives.
TABLE 3: Basic considerations about case's parameters.

\begin{tabular}{lc}
\hline$G_{P}$ & $3 \mathrm{PL}_{i}$ \\
\hline $\begin{array}{l}\text { Contract duration } \\
8 \text { years }\end{array}$ & Expected hardware cost $E\left[\eta_{h}\right]: \$ 2.5 \mathrm{M}$ \\
Budget constraint & Expected software cost $E\left[\eta_{a}\right]: \$ 1.5 \mathrm{M}$ \\
$\omega_{i}=\$ 20.0 \mathrm{M}$ & Breakeven: 5 years \\
Type T engine & Unit maintenance cost $\eta_{m}: \$ 0.2 \mathrm{M}$ \\
$n_{i}=300, S_{i}=15$ & Profit: $10 \%$ of $\eta_{m}$ \\
Unit cost $D_{i}=\$ 0.5 \mathrm{M}$ & $E\left[B_{i}\right]=11$ \\
Max. penalty rate $v_{i}=$ & $E\left[u_{i}\right]=14 /$ year \\
$10 \%$ &
\end{tabular}

\section{Numerical Analysis}

In this section, the subsequent quantitative analysis presents how $G_{P}$ starts to coordinate a $G_{P}-3 \mathrm{PL}_{i}$ service supply chain with a chosen $3 \mathrm{PL}_{i}$, who accepts the technology transfer from ith system's OEM through an arms offset program in Taiwan. This typical practice demonstrates how the proposed framework can be applied into an eight-year after-sales support service. Notably, the proposed framework reasonably specifies budget-balance constraints, regulations, costs, cost premium, and penalty parameters.

Total $N=150$ military twin-engine helicopters are deployed in Army, Navy, and Air Force. The helicopters are powered by type $\mathrm{T}$ turboshaft engine, plus $5 \%$ for inventory by $G_{P}$. Table 3 represents considerations under a general operation (i.e., without critical mission requirements), cost constrain, and maintenance capability.

Based on giving a selected level for availability and incentives to support $3 \mathrm{PL}_{i}$ 's software cost $\eta_{a}$ (i.e., the OEM's technical assistance) by arms offset program. $3 \mathrm{PL}_{i}$ starts to establish the maintenance capacity for the type $\mathrm{T}$ engine system. In this practice, we first derive the expected budget constrain, which meets the large procurement definition's threshold in the "Enforcement Rules of Government Procurement" in $G_{P}$. Thus, the maximum penalty rate $\operatorname{Max} v_{i} \approx 0.1$. Next, in real practice, the maximum cost reduction $\operatorname{Max} a_{i} \approx$ $0.1 E\left[c_{i}\right]$ (i.e., $k_{i}=1 / a_{i} \approx 0.46$ ), and the cost premium weighting factor $\max \alpha_{i}=\eta_{i} / C_{i} \approx 0.08$. Additionally, 
TABLE 4: The numerical results of each scheme with $r_{i}=26$.

\begin{tabular}{lccccccccc}
\hline & $r_{i}=26$ & \multicolumn{3}{c}{$G_{P}$ 's payment (million dollars) } & \multicolumn{3}{c}{ 3PL's profit (million dollars) } \\
$\operatorname{Var}\left[B_{i} \mid S_{i}\right]$ & $\operatorname{Var}\left[\varepsilon_{i}\right]$ & $T_{F}$ & $T_{P}$ & $T_{C}$ & $T_{B}$ & $T_{F}$ & $T_{P}$ & $T_{C}$ \\
\hline 1 & 0.01 & 20.00 & 19.81 & 18.59 & 18.39 & 2.31 & 0.84 & 2.52 \\
1 & 0.05 & 20.00 & 19.81 & 18.59 & 18.40 & 2.27 & 0.32 & 2.08 \\
1 & 0.10 & 20.00 & 19.81 & 18.59 & 18.40 & 2.22 & -0.33 & 1.53 \\
1 & 0.15 & 20.00 & 19.81 & 18.60 & 18.40 & 2.17 & -0.98 & 0.98 \\
1 & 0.20 & 20.00 & 19.81 & 18.60 & 18.41 & 2.12 & -1.63 & 0.43 \\
\hline 2 & 0.01 & 20.00 & 19.83 & 18.59 & 18.42 & 2.31 & 0.81 & 2.52 \\
2 & 0.05 & 20.00 & 19.83 & 18.59 & 18.42 & 2.27 & 0.29 & 2.08 \\
2 & 0.10 & 20.00 & 19.83 & 18.59 & 18.43 & 2.22 & -0.36 & 1.53 \\
2 & 0.15 & 20.00 & 19.83 & 18.60 & 18.43 & 2.17 & -1.01 & 0.93 \\
2 & 0.20 & 20.00 & 19.83 & 18.60 & 18.43 & 2.12 & -1.66 & 0.43 \\
\hline
\end{tabular}

TABle 5: Descriptive statistics for $G_{P}$ 's expected budget payments.

\begin{tabular}{|c|c|c|c|c|}
\hline (\$USM) & $T_{F}$ & $T_{P}$ & $T_{C}$ & $T_{B}$ \\
\hline Mean & 20.000 & 19.818 & 18.594 & 18.412 \\
\hline Standard deviation & 0.000 & 0.027 & 0.007 & 0.032 \\
\hline Mode & 20.000 & 19.780 & 18.592 & 18.366 \\
\hline Median & 20.000 & 19.814 & 18.618 & 18.408 \\
\hline Variance & 0.000 & 0.001 & 0.000 & 0.001 \\
\hline$E\left[U_{p}\left(T_{i}\left(C_{i}, B_{i}\right)\right) \mid a_{i}, S_{i}\right]$ & 20.000 & 19.818 & 18.594 & 18.412 \\
\hline
\end{tabular}

the risk aversion $0 \leq r_{i} \leq 51, \forall r_{i} \in R^{+}$, can be determined by giving $\operatorname{Max} \operatorname{Var}\left[B_{i}\right] \approx 0.2 E\left[B_{i}\right]$ and $\operatorname{Max} \operatorname{Var}\left[\varepsilon_{i}\right] \approx 0.2 C_{i}$. Hence, the required numerical solutions for all four schemes can be determined in Table 4 by giving $r_{i}=26$.

4.1. $G_{P}$ 's Expected Payment and Preference. This subsection considers uncertainties of four various contract schemes by setting the coefficients that are positively correlated (i.e., $\left.\operatorname{Var}\left[\varepsilon_{i}\right] \propto \operatorname{Var}\left[B_{i} \mid S_{i}\right]\right)$ to determine $G_{P}$ 's payment and rational preference. Notably, consider that $E\left[U_{p}\left(T_{i}\left(C_{i}, B_{i}\right)\right)\right.$ | $\left.a_{i}, S_{i}\right]$ is a stationary stochastic process by giving $r_{i} \in(0,51) \in$ $Z, \operatorname{Var}\left[B_{i} \mid S_{i}\right] \in(1,2) \in Z$, and $\operatorname{Var}\left[\varepsilon_{i}\right] \in(0.01,0.2)$ with interval 0.01 which allows to calculate the frequency of uniform discrete random variable for every possible payment (2,080 solutions for each scheme) because there are same probabilities:

$$
\begin{aligned}
E\left[U_{p}\left(T_{i}\left(C_{i}, B_{i}\right)\right) \mid a_{i}, S_{i}\right] & \\
= & \frac{\sum_{r_{i}} \sum_{B_{i}} \sum_{\operatorname{Var}\left(\varepsilon_{i}\right)} T_{i}\left(C_{i}, B_{i}\right)}{q_{i}},
\end{aligned}
$$

where $q_{i}$ denotes the frequency summation in $E\left[U_{p}\left(T_{i}\left(C_{i}\right.\right.\right.$, $\left.\left.\left.B_{i}\right)\right) \mid a_{i}, S_{i}\right]$ (i.e., $\left.q_{i}=2,080\right)$. Hence, $G_{p}$ 's histogram and the descriptive statistics for payments can be derived as Figure 3 and Table 5.

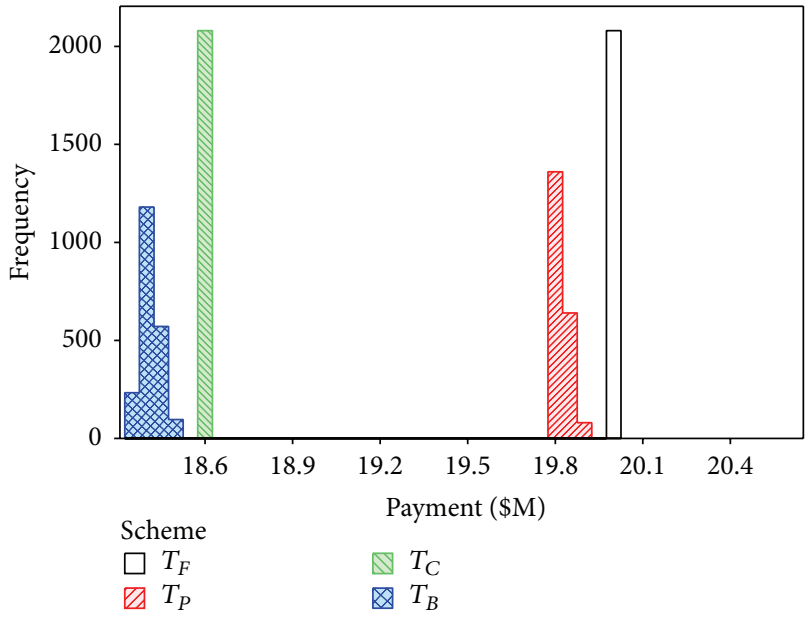

FIGURE 3: Frequency for numerical solutions of $G_{P}$ 's expected payments.

Furthermore, the payments of four schemes can be resulted by ordered as

$$
\begin{aligned}
E\left[U_{p}\left(T_{F}\left(C_{i}, B_{i}\right)\right)\right] & >E\left[U_{p}\left(T_{P}\left(C_{i}, B_{i}\right)\right)\right] \\
& >E\left[U_{p}\left(T_{C}\left(C_{i}, B_{i}\right)\right)\right] \\
& >E\left[U_{p}\left(T_{B}\left(C_{i}, B_{i}\right)\right)\right] .
\end{aligned}
$$



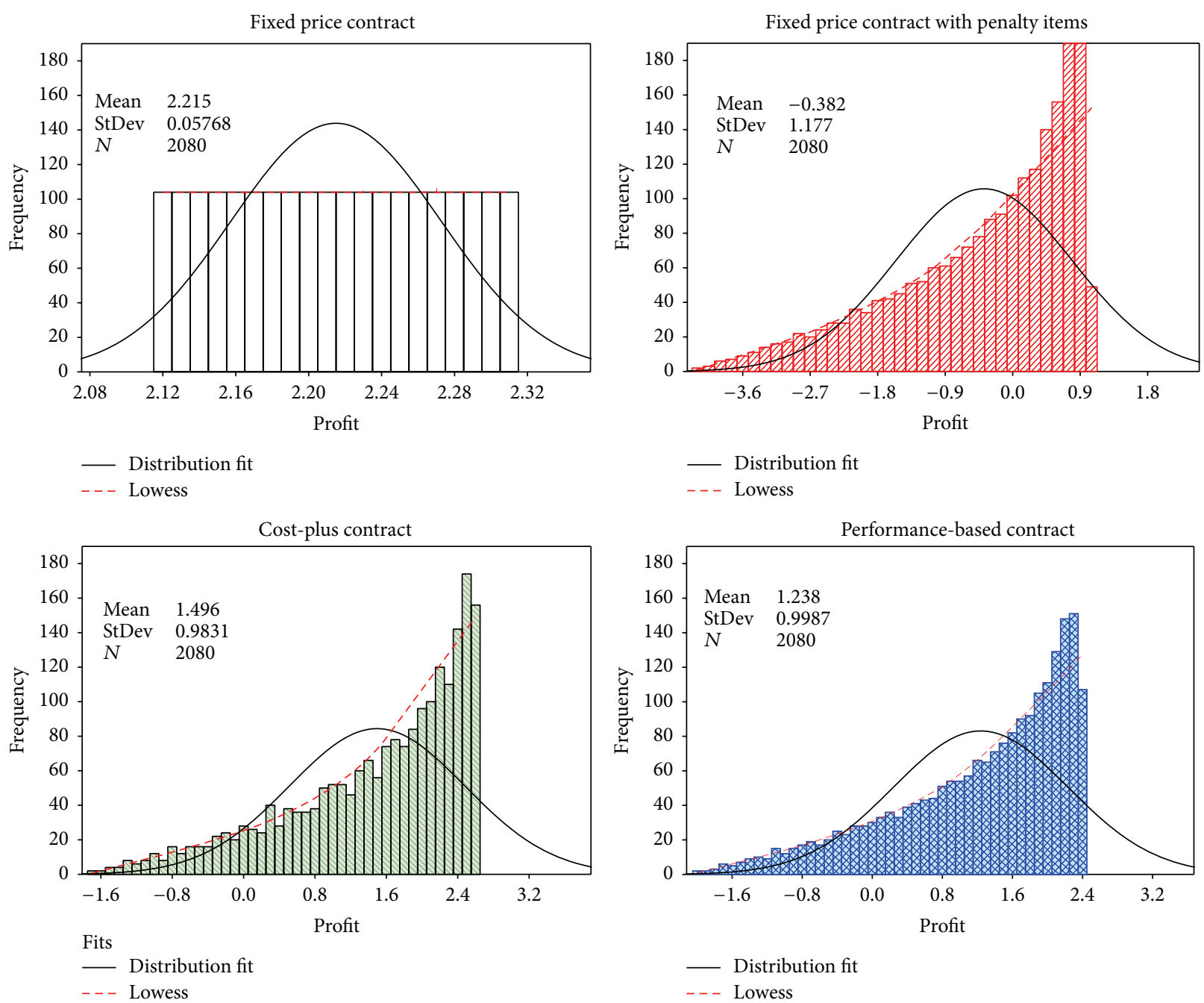

FIGURE 4: Frequency for numerical solutions of $3 \mathrm{PL}_{i}$ 's expected profits.

Thus $G_{P}$ 's rational preference can result as

$$
T_{B}\left(C_{i}, B_{i}\right)>T_{C}\left(C_{i}, B_{i}\right)>T_{P}\left(C_{i}, B_{i}\right)>T_{F}\left(C_{i}, B_{i}\right) .
$$

Based on the order steps of play by Nagarajan and Sošić [27] and the numerical results, $G_{P}$ will rationally offer the robust $T_{B}\left(C_{i}, B_{i}\right)$ scheme to $3 \mathrm{PL}_{i}$ as $G_{P}$ 's first offer for $G_{P}-$ $3 \mathrm{PL}_{i}$ coordinating problem. Notably, various uncertainties (i.e., $\operatorname{Var}\left[B_{i} \mid S_{i}\right]$, $\operatorname{Var}\left[\varepsilon_{i}\right]$ and $r_{i}$ ) do not affect the $G_{P}$ 's expected payments because numerical solutions indicate the expected payments are maintained as certain constant in each scheme. Hence, we conclude the proposed decision framework success provides a robust scheme $\left(T_{B}\left(C_{i}, B_{i}\right)\right)$ as dominating strategy for $G_{P}-3 \mathrm{PL}_{i}$ coordinating problem within a budget constraint.

4.2. 3PL $\mathrm{P}_{i}$ 's Expected Profit. $3 \mathrm{PL}_{i}$ 's expected profit function $E\left[U_{i}\left(T\left(C_{i}, B_{i}\right)-C_{i}\right)-\psi_{i}\left(a_{i}\right) \mid a_{i}, S_{i}\right]$ is also a stationary stochastic process by giving $r_{i}, \operatorname{Var}\left[B_{i} \mid S_{i}\right]$, and $\operatorname{Var}\left[\varepsilon_{i}\right]$. Thus the frequency of uniform discrete random variable can be calculated for every possible profit (i.e., 2,080 solutions in
TABLE 6: Descriptive statistics for 3PL ${ }_{i}$ 's expected profits.

\begin{tabular}{lcccc}
\hline (\$USM) & $T_{F}$ & $T_{P}$ & $T_{C}$ & $T_{B}$ \\
\hline Mean & 2.215 & -0.382 & 1.496 & 1.238 \\
Standard deviation & 0.058 & 1.177 & 0.983 & 0.998 \\
Mode & 2.310 & 0.995 & 2.629 & 2.409 \\
Median & 2.215 & -0.057 & 1.783 & 1.514 \\
Variance & 0.003 & 1.385 & 0.966 & 0.997 \\
$E\left[U_{i}\left(T_{i}\left(C_{i}, B_{i}\right)\right)\right]$ & 2.215 & -0.382 & 1.496 & 1.238 \\
\hline
\end{tabular}

each scheme) to determine the $E\left[U_{i}\left(T\left(C_{i}, B_{i}\right)-C_{i}\right)-\psi_{i}\left(a_{i}\right) \mid\right.$ $a_{i}, S_{i}$ ] by (3). $3 \mathrm{PL}_{i}$ 's histogram and the descriptive statistics can be derived as Figure 4 and Table 6 .

Furthermore, the profits of four schemes can result in order as

$$
\begin{aligned}
E\left[U_{i}\left(T_{F}\left(C_{i}, B_{i}\right)\right)\right] & >E\left[U_{i}\left(T_{C}\left(C_{i}, B_{i}\right)\right)\right] \\
& >E\left[U_{i}\left(T_{B}\left(C_{i}, B_{i}\right)\right)\right] \\
& >\left[U_{i}\left(T_{P}\left(C_{i}, B_{i}\right)\right)\right] .
\end{aligned}
$$


Based on Max $\operatorname{Arg} E\left[U_{i}\left(T\left(C_{i}, B_{i}\right)-C_{i}\right)-\psi_{i}\left(a_{i}\right) \mid a_{i}, S_{i}\right] \geq$ $0,3 \mathrm{PL}_{i}$ will rationally decline $T_{P}\left(C_{i}, B_{i}\right)$ contracting because only $E\left[U_{i}\left(T_{P}\left(C_{i}, B_{i}\right)\right)\right]<0$. Hence, $3 \mathrm{PL}_{i}$ 's rational preference can result as

$$
\begin{aligned}
E\left[U_{i}\left(T_{F}\left(C_{i}, B_{i}\right)\right)\right] & >E\left[U_{i}\left(T_{C}\left(C_{i}, B_{i}\right)\right)\right] \\
& >E\left[U_{i}\left(T_{B}\left(C_{i}, B_{i}\right)\right)\right] .
\end{aligned}
$$

\section{Conclusions}

In this paper, we propose a quantitative decision making framework to develop a predictable assessment for solving the unexplored coordinating problem for $G_{P}-3 P L$ service supply chain by the intervention of arms offset program. The proposed framework firstly formulates the objective functions for $G_{P}-3 \mathrm{PL}$ service supply chain to approximate equilibrium solutions by principle-agent model and secondly assesses the coordinating preference by normal-form game analysis with four schemes. Drawing from the proposed decision framework and analytical results by implementing a typical coordinating practice of $G_{P}-3 \mathrm{PL}$ service supply chain in Taiwan, the following conclusions help us to address the three research questions.

Firstly, regard the interaction of $G_{P}-3 P L$ service supply chain under arms offset program intervention. During the process, $G_{P}-3 \mathrm{PL}$ interacts on system availability and $G_{P}$ 's budget constraint toward a take-it-or-leave-it contract to achieve equilibrium solutions for $G_{P}$ 's minimal payment (i.e., budget constraint) and $3 \mathrm{PL}_{i}$ 's positive profit.

Secondly, how does the assessment consider the contracting decisions? $G_{P}$ concerns how to determine a minimal payment to enrich the economic utilities, ith system's availability, and $3 \mathrm{PL}_{i}$ concerns how to approach a maximal profit under $G_{P}$ 's preference contracting schemes. Furthermore, by implementing the coordinating practical $G_{P}$ $3 \mathrm{PL}$ practice in Taiwan, this paper demonstrates that the proposed decision framework is sufficient to formulate the coordinating problem for $G_{P}-3 \mathrm{PL}$ service supply chain to approximate expected solutions for all various contracting schemes. Notably, the proposed framework does not only provide $G_{P}$ 's expected budget-balance and rational preference for outsourcing decision, but also determines $3 \mathrm{PL}_{i}$ 's expected profit.

Thirdly, how does the quantifiable assessment approach bargaining equilibrium under various schemes? Additionally, how does the quantifiable assessment influence decisions for $G_{P}-3 \mathrm{PL}$ service supply chain relation? The proposed framework assesses $G_{P}$ 's rational preference for outsourcing decision by determining approximated solutions for all outsourcing schemes. Notably, the numerical analysis indicates uncertainties such as $\operatorname{Var}\left[B_{i} \mid S_{i}\right], \operatorname{Var}\left[\varepsilon_{i}\right]$ and $r_{i}$ do not affect $G_{P}$ 's expected payment because which are maintained as certain constant in each schemes. Hence the proposed framework can approach a predictable assessment for the coordinating problem for $G_{P}-3 \mathrm{PL}$ service supply chain.

This paper's innovation firstly investigates the unexplored coordinating problem for $G_{P}-3 P L$ service supply chain, which is induced by an arms offset program, and secondly presents a decision framework to assess the problem by considering the uncertainties arising from both support costs and system's availability. Specifically, this paper discovers incentive terms in contracting that exhibit complementarities, such that 3PL's cost reduction is induced by an arms offset program. Nevertheless, the limitation in this paper is that the proposed framework only provides a contracting strategy but ignores 3PL's efforts for improving system's availability because quantitative research on joint efforts between $G_{P}-3$ PL service supply chain and the OEM is still within the early stage.

\section{Conflict of Interests}

The authors declare that there is no conflict of interests regarding the publication of this paper.

\section{Acknowledgments}

The authors gratefully acknowledge the support by Ministry of Science and Technology, Taiwan, under Grants nos. MOST 103-2221-E-011-061-MY3 and MOST 104-2628-E-011010-MY3.

\section{References}

[1] S.-H. Kim, M. A. Cohen, and S. Netessine, "Performance contracting in after-sales service supply chains," Management Science, vol. 53, no. 12, pp. 1843-1858, 2007.

[2] T. Jin and P. Wang, "Planning performance based contracts considering reliability and uncertain system usage," Journal of the Operational Research Society, vol. 63, no. 10, pp. 1467-1478, 2012.

[3] W.-M. Lu and T.-C. Wang, "A fuzzy multi-criteria model for the industrial cooperation program transaction strategies: a case in Taiwan," Expert Systems with Applications, vol. 38, no. 3, pp. 1490-1500, 2011.

[4] T. K. Taylor, "Modeling offset policy in government procurement," Journal of Policy Modeling, vol. 25, no. 9, pp. 985-998, 2003.

[5] M.-C. Tien and C.-C. Yang, "Taiwan's ICP mechanism-a review and a stage approach," Technological Forecasting and Social Change, vol. 72, no. 1, pp. 29-48, 2005.

[6] S.-H. Kim, M. A. Cohen, S. Netessine, and S. Veeraraghavan, "Contracting for infrequent restoration and recovery of mission-critical systems," Management Science, vol. 56, no. 9, pp. 1551-1567, 2010.

[7] R. Oliva and R. Kallenberg, "Managing the transition from products to services," International Journal of Service Industry Management, vol. 14, no. 2, pp. 160-172, 2003.

[8] A. Sols, D. Nowicki, and D. Verma, "n-dimensional effectiveness metric-compensating reward scheme in performance-based logistics contracts," Systems Engineering, vol. 11, no. 2, pp. 93106, 2008.

[9] W. Wang, "A model for maintenance service contract design, negotiation and optimization," European Journal of Operational Research, vol. 201, no. 1, pp. 239-246, 2010.

[10] F. M. Scherer, "The theory of contractual incentives for cost reduction," The Quarterly Journal of Economics, vol. 78, no. 2, pp. 257-280, 1964. 
[11] R. P. McAfee and J. McMillan, "Bidding for contracts: a principal-agent analysis," RAND Journal of Economics (RAND Journal of Economics), vol. 17, no. 3, pp. 326-338, 1986.

[12] H. H. Martin, "Contracting out maintenance and a plan for future research," Journal of Quality in Maintenance Engineering, vol. 3, no. 2, pp. 81-90, 1997.

[13] E. Ashgarizadeh and D. N. Murthy, "Service contracts: a stochastic model," Mathematical and Computer Modelling, vol. 31, no. 10-12, pp. 11-20, 2000.

[14] R. A. Bowman and J. Schmee, "Pricing and managing a maintenance contract for a fleet of aircraft engines," Simulation, vol. 76, no. 2, pp. 69-77, 2001.

[15] K. B. Öner, G. P. Kiesmüller, and G. J. van Houtum, "Optimization of component reliability in the design phase of capital goods," European Journal of Operational Research, vol. 205, no. 3, pp. 615-624, 2010.

[16] F. Fang and T.-N. Wong, "Applying hybrid case-based reasoning in agent-based negotiations for supply chain management," Expert Systems with Applications, vol. 37, no. 12, pp. 8322-8332, 2010.

[17] C. Yu and T. N. Wong, "An agent-based negotiation model for supplier selection of multiple products with synergy effect," Expert Systems with Applications, vol. 42, no. 1, pp. 223-237, 2015.

[18] T. Jin, Z. Tian, and M. Xie, "A game-theoretical approach for optimizing maintenance, spares and service capacity in performance contracting," International Journal of Production Economics, vol. 161, pp. 31-43, 2015.

[19] W. Liu, X. Zhao, and R. Wu, "Revenue-sharing contract models for logistics service supply chains with mass customization service," Mathematical Problems in Engineering, vol. 2015, Article ID 572624, 21 pages, 2015.

[20] W. Kuo and R. Wan, "Recent advances in optimal reliability allocation," IEEE Transactions on Systems, Man, and Cybernetics, Part A: Systems and Humans, vol. 37, no. 2, pp. 143-156, 2007.

[21] J.-B. Sheu, "Bargaining framework for competitive green supply chains under governmental financial intervention," Transportation Research Part E: Logistics and Transportation Review, vol. 47, no. 5, pp. 573-592, 2011.

[22] E. W. T. Ngai, S. Peng, P. Alexander, and K. K. L. Moon, "Decision support and intelligent systems in the textile and apparel supply chain: an academic review of research articles," Expert Systems with Applications, vol. 41, no. 1, pp. 81-91, 2014.

[23] Y. Duan, G. Li, and J. Huo, "Supply chain coordination for fixed lifetime products with permissible delay in payments," Mathematical Problems in Engineering, vol. 2014, Article ID 649189, 11 pages, 2014.

[24] Y.-K. Lin, J.-J. Lin, and R.-H. Yeh, "A dominant maintenance strategy assessment model for localized third-party logistics service under performance-based consideration," Quality Technology \& Quantitative Management, vol. 10, no. 2, pp. 221-240, 2013.

[25] F. Chen, "Salesforce incentives, market information, and production/inventory planning," Management Science, vol. 51, no. 1, pp. 60-75, 2005.

[26] J. J. Laffont and J. Tirole, A Theory of Incentives in Procurement and Regulation, MIT Press, Cambridge, UK, 1993.

[27] M. Nagarajan and G. Sošić, "Game-theoretic analysis of cooperation among supply chain agents: review and extensions," European Journal of Operational Research, vol. 187, no. 3, pp. 719-745, 2008.
[28] A.-C. Chiang and K. Wainwright, Fundamental Methods of Mathematical Economics, McGraw-Hill Higher Education, New York, NY, USA, 4th edition, 2005. 


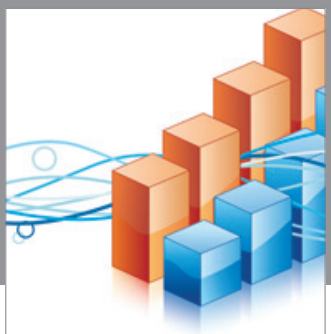

Advances in

Operations Research

vatem alat4

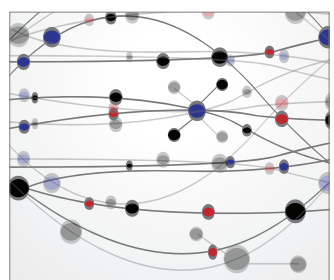

\section{The Scientific} World Journal
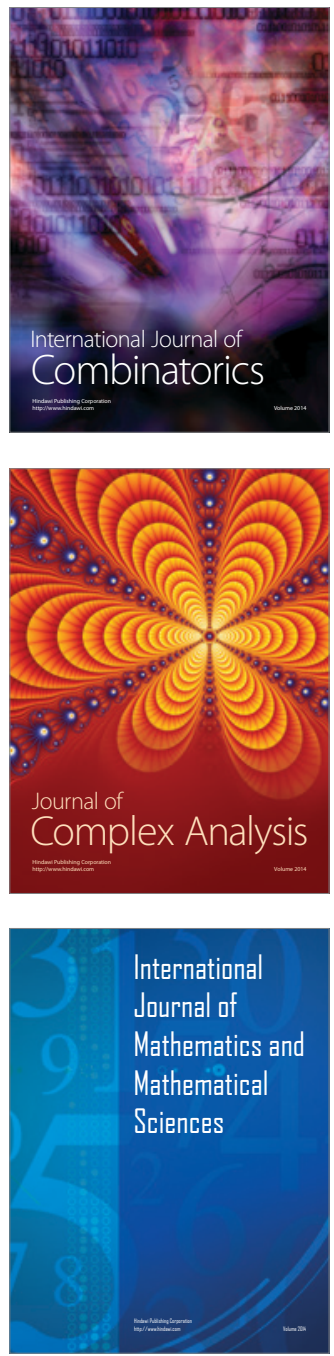
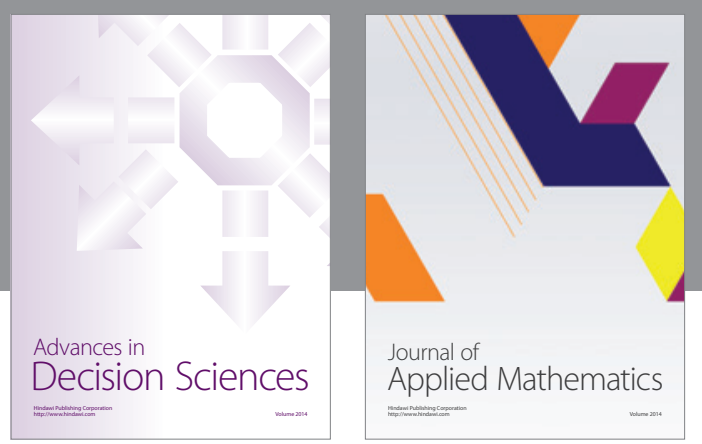

Algebra

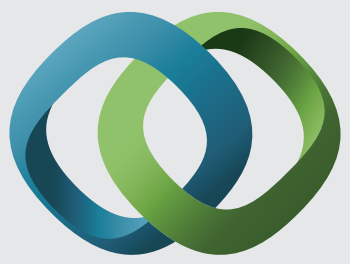

\section{Hindawi}

Submit your manuscripts at

http://www.hindawi.com
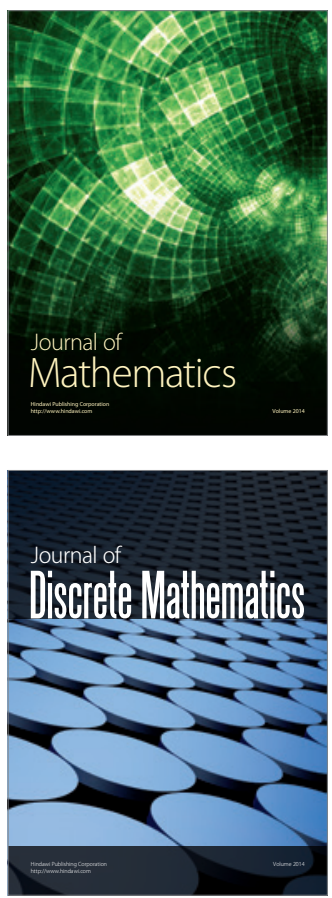

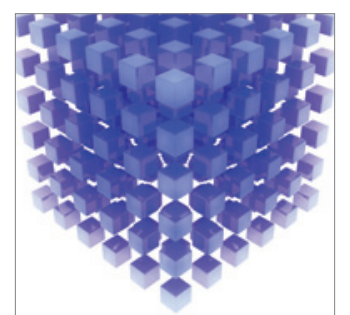

Mathematical Problems in Engineering
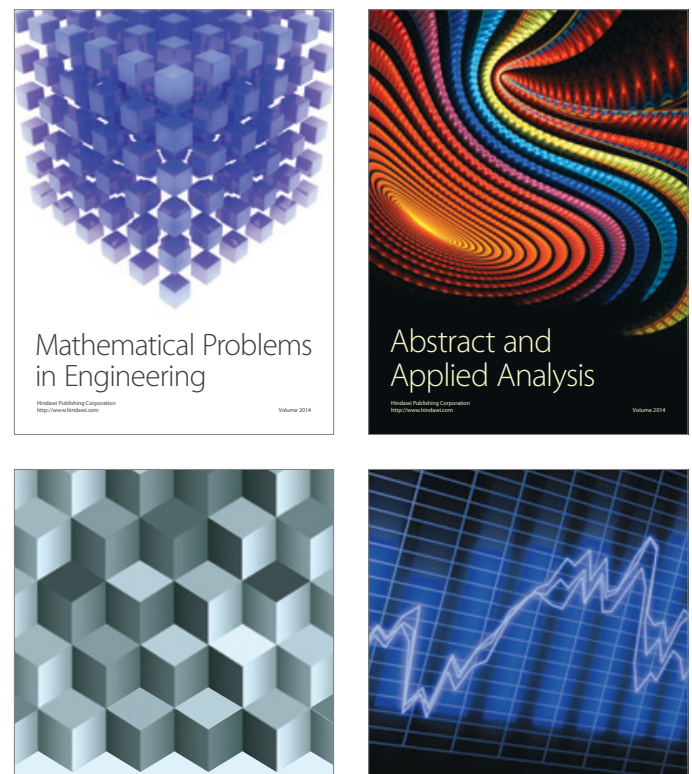

Journal of

Function Spaces

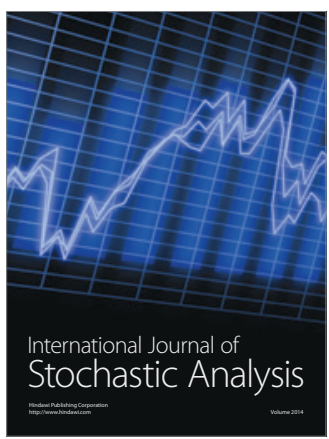

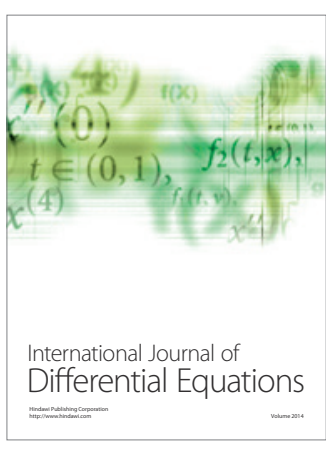
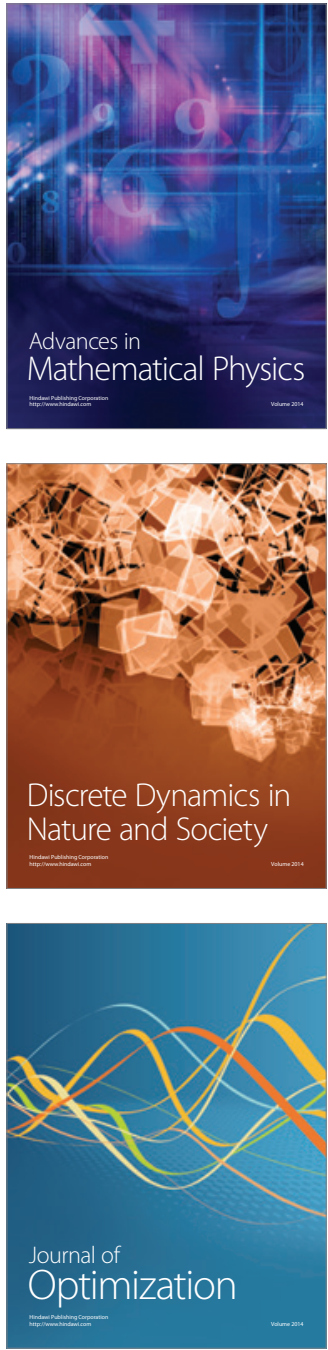